\title{
The tiny world of microRNAs in the cross hairs of the mammalian eye
}

\author{
Robert M. Lavker, ${ }^{\prime *}$ Jia-Yu' and David G. Ryan² \\ 'Department of Dermatology, Northwestern University, Chicago, IL 20611, USA \\ ${ }^{2}$ Department of Ophthalmology, Northwestern University, Chicago, IL 20611, USA \\ *Correspondence to: Tel: +1 312503 4315; Fax: +1 312503 4325; E-mail: r-lavker@northwestern.edu
}

Date received (in revised form): 8th January 2009

\section{Introduction}

Over the past ten years, it has become increasingly apparent that the repertoire of transcripts produced by any given eukaryotic genome is more diverse and abundant than originally thought and that a significant fraction of the genetic material of all organisms produces transcripts that do not encode proteins. ${ }^{1} \quad$ All organisms produce non-coding RNAs (ncRNAs), such as ribosomal RNAs (rRNAs), transfer RNAs (tRNAs), small nuclear RNAs (snRNAs) and small nucleolar RNAs (snoRNAs). ${ }^{2}$ Because of their central roles in the translation of messenger RNA (mRNA), these classes of ncRNAs have evolved little in billions of years. MicroRNAs (miRNAs), small interfering RNAs (siRNAs) and repeat-associated small interfering RNAs (rasiRNAs) belong to a group of ncRNAs commonly referred to as the small regulatory RNAs. ${ }^{1,3-5}$ Small regulatory RNAs are intimately associated with the discovery of RNA interference ${ }^{6-8}$ and the subsequent development of silencing technologies that has revolutionised the reverse genetic approach. ${ }^{9-11}$ For example, it is no longer necessary to conduct lengthy in vivo knockout approaches to determine gene function. It is no coincidence that members of the small regulatory RNA group have similar biogenic pathways ${ }^{12-14}$ and mechanisms of action ${ }^{15-17}$ and can sometimes only be distinguished either by their differing origins or by the type of targets they regulate. ${ }^{1,5}$ As their name implies, small regulatory RNAs are exceedingly small molecules, ranging in size from
21 to 25 nucleotides. ${ }^{1,3}$ Yet, despite their tiny stature, these small RNA molecules exert profound and potent influences on a diverse array of biological systems (see below).

MiRNAs, more than any other class of regulatory RNA, have drawn the lion's share of attention in recent years. MiRNAs have been found in diverse organisms from both the plant and animal kingdoms. ${ }^{18-22}$ Their numbers have increased exponentially since the first descriptive reports of the two founding members of their class, lin-4 and let-7, were published. ${ }^{23,24}$ A central online database, the miRNA Registry (http://www.microrna. sanger.ac.uk/sequences), was created in 2004 to accommodate the expanding numbers of newly identified miRNAs. ${ }^{25}$ The database incorporated a previously developed system for the acceptance and annotation of newly identified sequences as miRNAs. ${ }^{26}$ The miRNA Registry currently lists 5,922 distinct miRNA sequences from the genomes of 58 species. $^{27}$ MiRNA genes account for between 1 and 2 per cent of the total gene pool of an organism. Many miRNAs are phylogenetically conserved. ${ }^{18,21,22,28}$ For example, 60 per cent of the 533 unique human miRNAs are also found in mice. $^{27} \mathrm{~A}$ smaller but significant number of these miRNAs, such as let-7, are highly conserved across a wider range of species, reflecting important biological functions. ${ }^{18,20,21,28,29}$ MiRNAs exhibit as wide a variety of developmental and tissue distribution patterns as we are accustomed to seeing with the more commonly encountered proteincoding mRNAs. ${ }^{30}$ Many miRNAs are expressed in 
a highly tissue-specific manner. ${ }^{19,31-33}$ It is important to note that those miRNAs that are conserved in sequence across species also show a high degree of similarity in their expression profiles.

Of the known mouse or human miRNAs, more than 70 per cent are located in highly organised transcription units. ${ }^{34}$ Based on their location in the human genome, miRNAs can be further classified into three categories: (i) exonic miRNAs in noncoding gene transcripts; (ii) intronic miRNAs in non-coding gene transcripts; and (iii) intronic miRNAs in protein-coding gene transcripts. Transcription of miRNA genes is mediated by RNA polymerase II (pol II). ${ }^{35}$ The primary transcripts of miRNAs (pri-miRNAs) are several kilobases $(\mathrm{kb})$ long and contain a $5^{\prime} 7$-methyl guanosine cap. ${ }^{36}$ This indicates that, similar to other genes transcribed by pol II, miRNAs probably also follow the same set of intricate regulatory controls that might be specific to different developmental stages and tissues. Some intergenic miRNAs, such as lin-4 and let-7 in Caenorhabditis elegans, have independent transcription units, including a promoter, transcript sequence and terminator, and therefore do not overlap with other genes in their biogenesis. The pri-miRNAs are processed to produce individual precursors (pre-miRNAs). Two RNase III enzymes are involved in miRNA biogenesis: Drosha and Dicer. Pri-miRNA transcripts are processed by the RNase III enzyme, Drosha (Drosha-Pasha/ DiGeorge critical region-8 [DGCR8] complex), in the nucleus to give rise to an intermediate miRNA form referred to as pre-miRNA. ${ }^{37}$ Pre-miRNAs are stem-looped RNAs of approximately 60 base pairs or longer. In animal cells, pre-miRNAs are exported from the nucleus to the cytoplasm via Exportin-5, ${ }^{38}$ where they are further processed by Dicer to produce mature miRNAs. The mature miRNAs are incorporated into the RNA-induced silencing complex (RISC) and interact directly with the Argonaute protein eIF2C2. ${ }^{39}$ MiRNAs direct RISC to their targets and downregulate gene expression. This downregulation is known to be an outcome of either target mRNA cleavage or translational repression. The selection of one or other of these two options is based on the degree of complementarity between the miRNA seed sequence (first 2-8 base sequence of a miRNA) and the target-gene binding sequence (mostly in the $3^{\prime}$ untranslated region (UTR) of the target gene). In plants, it has been shown that if there is perfect complementarity between the miRNA seed sequence and the target mRNA, the target mRNA is degraded; if there is only partial complementarity, translation of the mRNA is inhibited (usually after the translation initiation step). MiRNAs are believed to regulate around 30 per cent of protein-coding genes. Although the exact function of the majority of miRNAs remains unknown, these endogenous silencing RNAs have been shown to play important roles in development and differentiation, ${ }^{33,40-43}$ cellular stress responses, ${ }^{44}$ stem cell regulation $^{45-48}$ and cancer. ${ }^{49-54}$

\section{MicroRNAs are linked to development and differentiation}

As mentioned previously, many miRNAs appear to be expressed in a tissue-specific and/or developmentally regulated manner. One of the earliest insights into miRNA function was the identification of lin-4 and let-7 as miRNAs in C. elegans, which were required for cell fate switches at specific times during larval development. ${ }^{23,24}$ Two other C. elegans miRNAs, Lys-6 and mir-273, have been shown to be involved in the control of left/ right neuronal asymmetry. ${ }^{55,56}$ Those miRNAs, such as the Drosophila bantam gene, repress apoptosis and promote cell proliferation in the developing fly. ${ }^{57}$ Another Drosophila miRNA gene, miR-14, also plays a role in apoptosis and fat storage. ${ }^{42}$ More recently, Drosophila miR-7 was shown to be activated in cells that differentiate into photoreceptors, and this was mediated by epidermal growth factor receptor (EGFR) signalling. $^{58}$ In the mouse, miR-181 is restricted to haematopoietic cells, and the forced expression of this miRNA in progenitor cells favours the development of $\mathrm{B}$ over $\mathrm{T}$ cells. ${ }^{59}$ Interestingly, this miRNA is also present in the corneal epithelium $^{60}$ and will be discussed later. Mouse miR-196a is involved in homeobox gene regulation. ${ }^{61}$ In cultures of human primary subcutaneous pre-adipocytes, increasing the miR-143 
levels induced adipocyte formation, while inhibition of this miRNA blocked adipocyte differentiation. ${ }^{40}$ In a study of muscle differentiation, miR-206, -1 and -133 were shown to be critical for myogenesis. ${ }^{62}$ Similarly, miR-1 has been demonstrated to target Hand2, a gene encoding a transcription factor that promotes ventricular cardiomyocyte growth. ${ }^{43}$

In a comprehensive study of the expression patterns of 119 miRNAs in adult organs from mice and humans, 30 miRNAs were found to be specifically expressed or enriched in a particular organ (eg the brain, lung, liver, skeletal muscle), suggestive of tissue-specific functions. Furthermore, a subset of brain miRNAs was upregulated when human and mouse embryonal carcinoma cells were induced to differentiate into neurones by retinoic acid, implicating these miRNAs in mammalian neuronal development or function. ${ }^{33}$ Similar tissue specificity for miRNA expression was recently reported for 115 vertebrate miRNAs during zebrafish embryonic development, indicative that miRNAs may be very important for differentiation and/or the maintenance of tissue identity. ${ }^{63}$ Taken together, the above findings suggest that miRNAs are involved in controlling cell fate during development and are important for proper differentiation.

\section{MicroRNAs and stem cell regulation}

There is increasing evidence that miRNAs can play a role in regulating stem cells, which, in turn, will affect tissue and organ development. Much of our understanding about miRNAs has come from experiments in which mutations are introduced into Dicer, the cytoplasmic enzyme required for processing miRNA precursors into mature effector RNA molecules. ${ }^{12,64}$ For example, disruption of the dicer-1 gene in mouse embryonic stem cells (ESCs) resulted in defects in: (i) division and proliferation ${ }^{47}$ and (ii) differentiation both in vitro and in vivo. ${ }^{46}$ Furthermore, loss of dicer 1 in mice leads to embryonic lethality due to a depletion of stem cells. ${ }^{45}$ Following mutation of dicer-1 in Drosophila, germline stem cells (GSCs) were delayed in the $\mathrm{G}-\mathrm{S}$ transition, which is dependent on the cyclin kinase inhibitor Dacapo (a homologue of the p21/p27 family of cyclin-dependent kinase inhibitors). ${ }^{65}$ It was hypothesised that miRNAs repressed Dacapo, thereby allowing GSCs to transit the G1/S checkpoint. This repression assures continuous cell division of GSCs, which generates an array of progressively developed egg chambers in ovarioles. ${ }^{65}$

Further evidence for a role for miRNAs in maintaining stem cell character comes from studies on the Argonaute proteins, which, along with Dicer, are core components of the RISC. ${ }^{66-68}$ Mutations in the Drosophila Argonaute protein piwi attenuate the self-renewing, asymmetric division of both male and female GSCs. ${ }^{69}$ Similar germline defects have been observed in C. elegans following a reduction in $P R G-1$ and $P R G-2$, genes that are closely related to piwi. ${ }^{69}$ The human piwi homologue, Hiwi, is expressed in $\mathrm{CD}_{3} 4^{+}$bone marrow stem cells, but not in more differentiated haematopoietic lineages. ${ }^{70}$ Furthermore, Hiwi overexpression has been noted in tumours derived from embryonic germ cells that maintain a stem cell character, indicating a possible role for Hiwi in maintaining stem cell division. ${ }^{71}$ Drosophila Argonate1 (dAgo1) mutations cause embryonic lethality, with a severe decrease in all types of neurones and glial cells, and it is thought that this phenotype might be due to a defect in cell cycle progression or cell survival. ${ }^{72}$ Mice that are null for Argonaute 2 exhibited severe defects in neural development, including failure to close the neural tube. ${ }^{73}$

The cloning of miRNAs revealed that distinct populations are found in mouse and human ESCs. In both cases, ESC-specific miRNAs were downregulated during development into embryoid bodies, suggesting that these miRNAs had roles in restricting cell differentiation. ${ }^{74-76}$ With respect to specific progenitor cells, elevation of miR-134 in mouse ESCs enhanced differentiation towards ectodermal lineages. ${ }^{77}$ The miR-17-92 locus promoted high proliferation, accompanied by an undifferentiated phenotype in lung epithelial progenitor cells. ${ }^{78}$ Several miRNAs, including miR-205, were highly expressed in mammary progenitor cells. ${ }^{79}$ Most recently, p63, a putative regulator of stem cell maintenance ${ }^{80-84}$ has been shown to be one of the targets of miR-203 in mouse epidermis. ${ }^{48}$ Collectively, the above studies 
demonstrate that: (i) there are unique stem cell miRNAs; (ii) the disruption of miRNA biogenesis affects stem cells in a variety of tissues, in a disparate group of organisms; and (iii) miRNAs may play fundamental roles in stem cell regulation.

\section{MicroRNAs are linked to the development of cancer}

Since stem cells are targets for neoplastic transformation, ${ }^{85-87}$ it is not surprising that altered expression of specific miRNAs are involved in tumorigenesis. For example, enforced expression of both c-myc and the mir-17-92 cluster, a group of miRNAs that are increased in human B-cell lymphomas and cell lines, promotes B-cell lymphomas in the mouse. ${ }^{88}$ This indicates that the mir-17-92 cluster is a potential human oncogene. ${ }^{88}$ In another study, investigators used a lymphoma cell line carrying a tetracycline-inducible form of $m y c$ to study the effects of $c-M \gamma c$ on miRNAs. ${ }^{89}$ Increased expression of $c-M \gamma c$ activated miRNAs, which negatively regulated the expression of the E2F1 transcription factor. This suggests that by negatively regulating E2F1, miRNAs could control $M \gamma c$-induced proliferation. ${ }^{89}$ In a study measuring the expression of human miRNAs in cancer samples, investigators reported a general downregulation of miRNAs in tumours compared with normal tissues. ${ }^{51}$ Collectively, these findings are consistent with the notion that in mammals, miRNAs can function to prevent cell division and drive terminal differentiation. ${ }^{90}$ Therefore, it was speculated that abnormalities in miRNA expression might contribute to the generation or maintenance of 'cancer stem cells', 51 which have been proposed to be responsible for cancerous growth (for a review of cancer stem cells see Miller et al. ${ }^{85}$ ).

\section{MicroRNAs are essential for the development and function of ocular tissues}

Compared with other systems, less attention has been directed towards evaluating the importance of miRNAs in the normal development and functioning of tissues that comprise the mammalian eye. One approach that has frequently been used to assess the requirement for miRNAs in tissue development and function is to block the production of functionally active miRNA molecules. MicroRNAs are processed by the RNaseIII enzyme, Dicer, from a non-functional $\sim 70$ nucleotide (nt) precursor RNA to an active $\sim 22-$ nt molecule. ${ }^{12,45}$ Unfortunately, mice carrying mutated Dicer alleles have been reported to die at embryonic day 7.5 (E7.5), preventing analysis of the requirements for miRNA activity in tissues that develop at later stages of embryogenesis and in the adult animal. ${ }^{45}$ To bypass this early lethality, floxed conditional Dicer alleles have been more widely employed. ${ }^{91-93}$ Mice carrying a combination of floxed Dicer alleles and a tissue-specific Cre transgene have been successful at blocking the production of functionally active miRNAs in a number of discrete tissues, both during embryogenesis and in the postnatal animal.

A Pax6-derived Le-Cre transgene, ${ }^{98}$ in combination with a floxed Dicer allele, ${ }^{93}$ has been used to block the processing of functionally active miRNAs in the surface ectoderm that gives rise to the lens, cornea and conjunctiva of the murine eye. Crosses

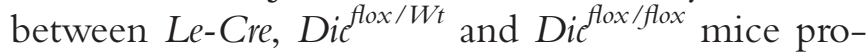
duced litters containing Le-Cre, Dieflox/flox pups with normal Mendelian frequencies, indicating that the $\mathrm{Le}$-Cre-driven ablation of Dicer function does not affect embryonic viability. The Le-Cre, Dic flox/flox pups were considerably smaller than their wild-type littermates, however, and had a short postnatal lifespan ( $\sim 2.5$ months). Their smaller size and shortened lifespan can be attributed to pancreatic insufficiency resulting from an additional domain of Cre expression in the endocrine cells of the pancreas. $^{98,99}$ This conclusion is in general agreement with an earlier report in which $P d x 1$-Cre-mediated ablation of Dicer in the pancreas resulted in early postnatal lethality. ${ }^{96}$

The Le-Cre, Dic flox/flox mice failed to open their eyes at day 14 , a phenotype that persisted throughout their adult life. Closer inspection of the eyelids of one-month-old Le-Cre, Die flox/flox $^{\text {animals }}$ revealed a partial opening towards the nasal domain 
of the fusion seam. An ocular globe was clearly evident beneath the surface, although its relative size was diminutive when compared with agematched wild-type globes. The inability to complete eyelid opening may simply be the result of a lack of pressure from a considerably smaller eye globe below the surface. Histological examination of the eyes of Le-Cre, Die flox/flox animals (Figure 1a, $c, e, g)$ revealed a complete absence of lens, iris and corneal epithelium. Conjunctival epithelium containing goblet cells covered the entire anterior ocular surface between the mucocutaneous junctional epithelium of the upper and lower eyelids (Figure 1a, c, e). The nictitating membrane was formed in Le-Cre, Die flox/flox animals. Stromal tissue in the area normally occupied by the cornea was vascularised and showed a high degree of cellularity (Figure 1c). Despite the failure in formation of

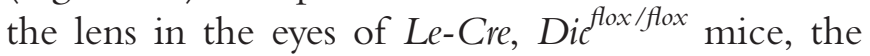
retina, including the pigmented epithelium of the choroid, and the ciliary body were appropriately organised and were indistinguishable from their counterpart tissues in the eyes of wild-type animals (Figure 1a, b).

The onset of Le-Cre transgene expression has been reported to occur at E9, and by E9.5 Cre-mediated recombination is seen in most cells of the surface ectoderm of the optic field. ${ }^{98}$ Between E9 and E9.5, the surface ectoderm receives inductive signals from the underlying optic vesicle that results in lens specification. ${ }^{100}$ Loss of miRNA activity in the surface ectoderm at this critical time point interferes in the specification of lens epithelium. As a consequence, the absence of a lens is most likely responsible for the failure in formation of the corneal epithelium, since lens tissue is required for corneal induction. ${ }^{100}$ At the 2008 Association for Research in Vision and Ophthalmology (ARVO) meeting, Piatigorsky and colleagues showed that in similar Dicer-ablated mice, no lens or cornea was evident at E12.5, reinforcing the conclusion that these tissues failed to form rather than degenerated. These findings underline the essential requirement for miRNA activity in the formation of the appropriate tissues that comprise the anterior segment of the mammalian eye.
It is of particular interest that the conjunctival epithelium, derived from a separate lineage than corneal epithelium, ${ }^{101}$ does not appear to be affected by the loss of miRNAs (Figure 1A, B, E, F). Furthermore, it is also noted that the appendage structures that reside in the eyelids, the meibomian glands and the eyelashes, are present and structurally well organised (Figure 1A, B, G, H). Ashery-Padan et al. ${ }^{98}$ report that the expression domain of the Le-Cre transgene is detected in all surface ectodermal-derived eye structures - namely, the lens, cornea, conjunctiva and skin of the eyelids. Our observations that conjunctival epithelium is unaffected by the loss of miRNA activity resemble those made by Yi et al. ${ }^{93}$ with a K14-Cre, Dic flox/flox mouse, where the interfollicular epidermis appeared normal. In the K14-Cre, Die flox/flox mice, however, the hair follicles evaginate into the epidermis, forming cyst-like structures. Unlike the hair follicles of the K14-Cre, Di flox/flox mice, the meibomian glands and eyelashes seen in the eyelids of Le-Cre, Dieflox/flox mice were not affected in a similar manner (Figure $1 \mathrm{G}$ ). One exception to the overtly normal make-up of the eyelids of Le-Cre, $D i e^{f l o x / f l o x}$ mice was the conspicuous absence of pigmented melanocytes in and around the mucocutaneous junctional epithelium (Figure 1G), an observation that needs further investigation.

Combination of the retinal-specific Chx10-Cre transgene with the Dicer floxed allele produced viable Chx10-Cre, Dic flox/flox progeny. ${ }^{102}$ Surprisingly, the normal complement of neural and glial cell types was present in the retinas of Chx10-Cre, Dic flox/flox mice. Furthermore, the various retinal cell types were found to occupy their expected laminar positions, and the gross retinal architecture of Chx10-Cre, Dic ${ }^{\text {flox/flox }}$ mice appeared relatively normal. The Chx10-Cre, $D i c^{f l o x / f l o x}$ mice displayed an inability to respond to light. More detailed histological examination of the retinas revealed the presence of morphologically abnormal structures. Rosettes of photoreceptors were observed in the retinas of postnatal day 16 animals. This architectural abnormality progressed to a more general cellular disorganisation and eventually gave rise to widespread retinal degeneration 

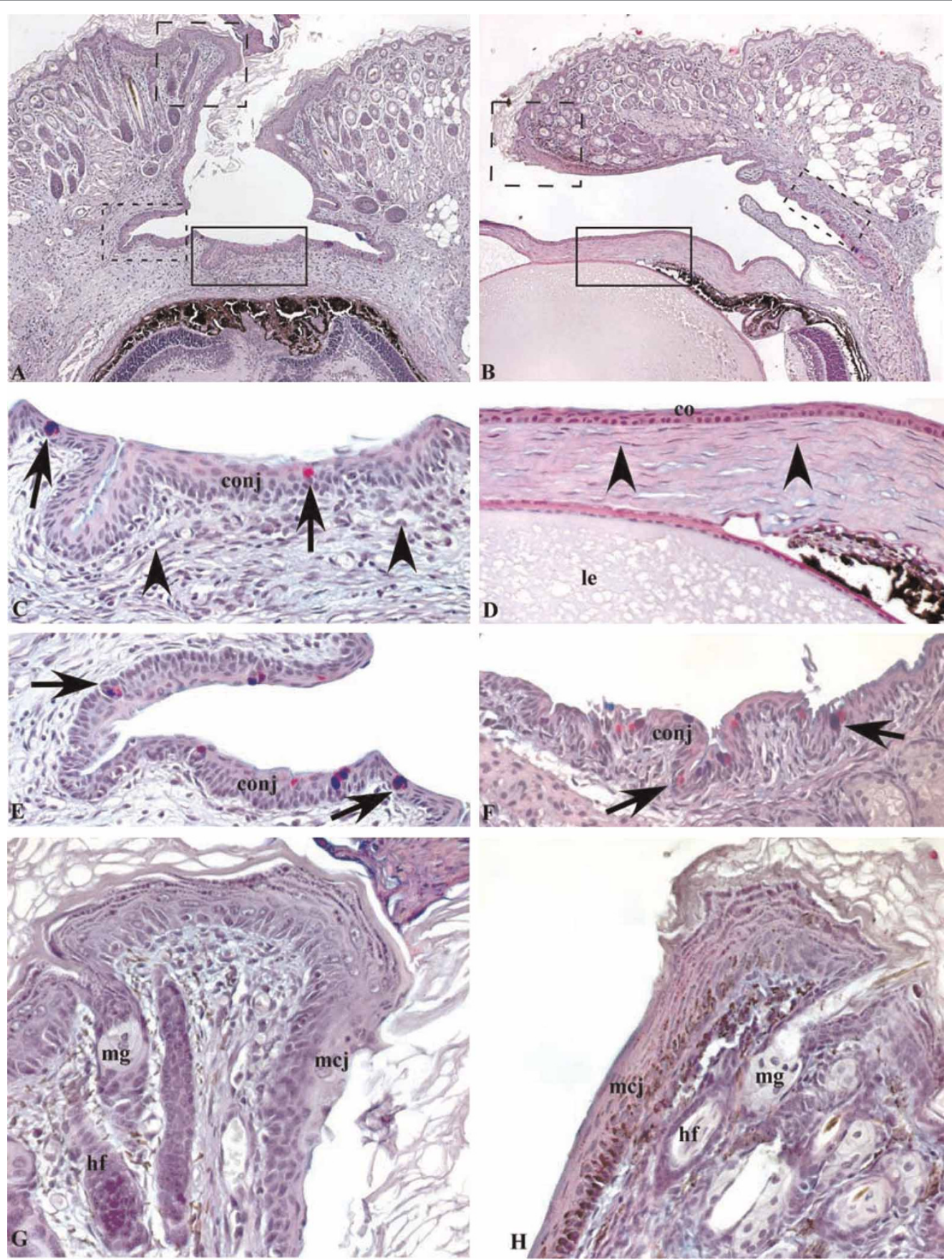

Figure I. Paraffin sections of the eyes of Le-Cre, Dic flox/flox animals (A, C, E, G) compared with age-matched (one-month) wild-type littermates $(B, D, F, H)$. Areas within solid boxes in $(A)$ and $(B)$ are shown in higher magnification in (C) and (D), respectively. The epithelium in (C) resembles the conjunctiva (conj), as evidenced by prominent goblet cells (arrows), and the stroma is vascularised (arrowheads); whereas the same region in the wild-type (D) clearly consists of a corneal epithelium (Co) and a stroma devoid of vessels and filled with keratocytes (arrows). Note the prominent lens (le) in the wild-type $(B, D)$ that is conspicuously missing in the Le-Cre, Dic flox/flox animals $(A, C)$. Areas within the small-dashed rectangles in $(A)$ and $(B)$ are shown in higher magnification in $(E)$ and $(F)$, respectively. Epithelium in $(E)$ and $(F)$ is conjunctival, as evidence by the presence of goblet cells (arrows). Areas within the lagged-dashed squares in (A) and (B) are shown in higher magnification in $(G)$ and $(H)$, respectively. The mucocutaneous junctional epithelium of the eye lid (mcj) appears similar in the Le-Cre, Dif flox/flox $(G)$ and wild-type $(H)$, except that the wild-type appears more heavily melanised. Portions of the meibomian gland $(\mathrm{mg})$ and hair follicles (hf) are noted in this region from both mice. 
as the animals aged. The retinal degeneration of Chx10-Cre, Dieflox/flox mice was accompanied by reduction in both scotopic and photopic electroretinogram responses. Interestingly, removal of a single allele of Dicer (haploinsufficency) resulted in loss of the light response throughout the lifespan of the animal but did not produce the morphological abnormalities seen in the completely null retinas, indicating that the loss of function in the retina is unrelated to the morphological abnormality. ${ }^{102}$ The observation that all retinal cell types were present and that as the animal aged the architecture of the tissue became more disorganised is somewhat reminiscent of observations made with hair follicles of the K14-Cre, Die flox/flox mice. In these mice, all cells normally present in the hair follicle were formed but the organisation of the follicular structure in relation to the epidermis was abnormal. ${ }^{93}$ Taken together, these results underscore the important role that miRNAs play in proper tissue morphogenesis, but these approaches do not provide information on the role that individual miRNAs play in regulating the various tissues of the eye.

\section{MiRNA expression and distribution in the corneal and lens epithelia}

\section{Corneal epithelium}

In an early study of adult mice, miRNAs were characterised by cloning the $\sim 21-n t$ RNAs from a variety of tissues, including the whole eye. ${ }^{32}$ Six miRNAs (miR-181, -182, -183, -184, -204 and -205) were exclusively found in the eye; however, no attempt was made to determine their location. The authors' laboratory was the first to elucidate the expression patterns of miRNAs in the mouse cornea and lens. ${ }^{60} \mathrm{~A}$ multifaceted approach was employed, combining miRNA microarrays, northern blots and in situ hybridisation techniques. We found that most ocular miRNAs were preferentially expressed in a tissue-restricted manner. For example, miR-184 had the highest hybridisation signal in corneal epithelium, and northern blot analysis indicated that this miRNA was preferentially expressed in the corneal epithelium. A strong in situ hybridisation signal for miR-184 was detected primarily in the basal and immediately suprabasal cells of the corneal epithelium. Expression of miR-184 was absent in the limbal and conjunctival epithelium, the mucocutaneous junctional epithelium of the eyelid, meibomian glands and eyelid epidermis, confirming the corneal epithelial enrichment of this miRNA. By contrast, miR-205, which had the second highest hybridisation signal in corneal epithelium, exhibited a broad range of expression within many stratified squamous epithelia. Furthermore, this miRNA was detected throughout the entire corneal, limbal and conjunctival epithelia, as well in the adult mouse epidermis. ${ }^{60}$ Thus, the broad range of expression observed for miR-205 within many stratified squamous epithelia suggests that it represents a more generalised epithelial miRNA. Consistent with this idea, when small RNAs (18$25 \mathrm{nt}$ ) were cloned and sequenced from embryonic (E17.5) mouse epidermis, mir-205 was highly expressed. ${ }^{93}$ Therefore, with respect to the corneal epithelium, the restricted expression of miR-184 highlights the distinct nature of this ectodermal lineage. Our findings with respect to the expression of miR-184 in the corneal epithelium were confirmed in a more recent survey of miRNAs and the eye. $^{103}$

\section{Lens epithelium}

Similar to the corneal epithelium, when analysed by array hybridisation, miR-184 was the most abundant miRNA in the mouse lens epithelium. ${ }^{60}$ Furthermore, several of the other highly expressed corneal epithelial miRNAs (eg mir-26a, -31, -125b and -181) also had strong hybridisation signals in the lens epithelium. This is not surprising, given the role that the lens plays in organising the anterior segment. ${ }^{104,105}$ In the adult lens, miR-184 was differentially expressed, with a strong signal detected in many of the cells of the germinative zone, whereas only a few cells of the anterior zone expressed miR-184. ${ }^{60}$ By contrast, an equal signal was detected for miR-204 in both the germinative and anterior zones. ${ }^{60}$ The findings on miR-184 expression in mouse lens epithelium were 
confirmed in a recent study. ${ }^{103}$ miRNA expression profiling of the adult newt lens also revealed the presence of miR-184, -181, -124, -204 and -125 . $^{106,107}$ Some miRNAs, for example let-7, were observed to be downregulated in the dorsal iris during the early events of newt lens regeneration, while other miRNAs, for example miR-148 were observed to be upregulated in the ventral iris. The authors speculated that these miRNAs might be acting as positive and/or negative regulators with respect to regeneration. ${ }^{107}$

\section{Functional significance of miRNAs in the corneal epithelium}

While miRNA expression profiling studies have provided information on the distribution of miRNAs within the corneal and lens epithelia, they are primarily descriptive and do not address directly the functional role(s) that these inhibitory RNAs play in these two tissues. Despite the fact that miRNAs have been predicted to regulate thousands of mammalian genes, ${ }^{108}$ few targets have been validated experimentally for the great majority of these miRNAs. Furthermore, with the exception of the recent demonstration that a p63-related family member is negatively regulated by miR-203, ${ }^{48}$ little is known about stratified squamous epithelial miRNA targets. Identification of target proteins that are regulated by miRNAs is the best way to ascertain the function of a specific miRNA. miR-184 and miR-205 have been focused on because of their abundance in corneal epithelium. Furthermore, bioinformatics analyses suggested that, in humans, the SH2-containing inositol phosphatase-2 (SHIP2) $3^{\prime}$ UTR is a putative target of both miR-184 and miR-205. ${ }^{109}$ To test this prediction, luciferase reporter assays were used in HeLa cells, and these cells were co-transfected with a miR-184 or miR-205 mimic and luciferase reporter constructs carrying the entire $3^{\prime}$ UTR of SHIP2 mRNA. ${ }^{110}$ In cells treated with miR-205, a marked reduction $(\sim 50$ per cent) was found in luciferase activity; however, no reduction in luciferase activity was seen in transfectants expressing miR-184. This suggested that
miR-205 inhibited SHIP2, whereas miR-184 did not. Interestingly, co-transfection of both miR-184 and -205 prevented miR-205-mediated downregulation of the luciferase activity for the SHIP2 construct. Mutation of the bases required for miR-184 and -205 binding on the SHIP2 molecule confirmed the observation that miR-184 prevented miR-205 from negatively regulating SHIP2. To validate SHIP2 as a target of mir-205, a mir-205 mimic was used to knock-down SHIP2 in HeLa cells, which have negligible endogenous levels of mir-205. Treatment with the miR-205 mimic resulted in a marked reduction in endogenous SHIP2 expression on Western blots, while a nontargeting mimic and a miR-184 mimic had no effect. Importantly, co-transfection of miR-205 and miR-184 mimics in HeLa cells failed to reduce SHIP2 levels, confirming the luciferase data. This is extremely significant because, to the authors' knowledge, this is the first example where one miRNA abrogates the inhibitory function of another in a vertebrate system. It also points out the distinctiveness of the corneal epithelium with respect to SHIP2 regulation. ${ }^{110}$

Interfering with miR-205 function by using a synthetic antagomir, or by the ectopic expression of miR-184, led to a coordinated damping of the Akt signalling pathway. ${ }^{110}$ This was associated with a marked increase in keratinocyte apoptosis and cell death. Thus, one of the functions of miR-205 in keratinocytes may be to enhance cell survival (Figure 2a). The biological implications of this finding are highlighted by the authors' observations that aggressive squamous cell carcinoma (SCC) cells exhibited elevated levels of miR-205. This was associated with a concomitant reduction in SHIP2 levels and markedly increased levels of phosphorylated Akt and phosphorylated BAD. This suggests that miR-205 may be functioning to enhance tumorigenesis (Figure 2c) and, conversely, that SHIP2 might be functioning as a tumour suppressor in SCCs, with both acting through the AKT pathway. ${ }^{110}$

It is worthwhile to speculate on why the corneal epithelium requires such a unique regulation of miR-205 and/or SHIP2 (Figure 2b). The idea that SHIP2 might function as a tumour suppressor 


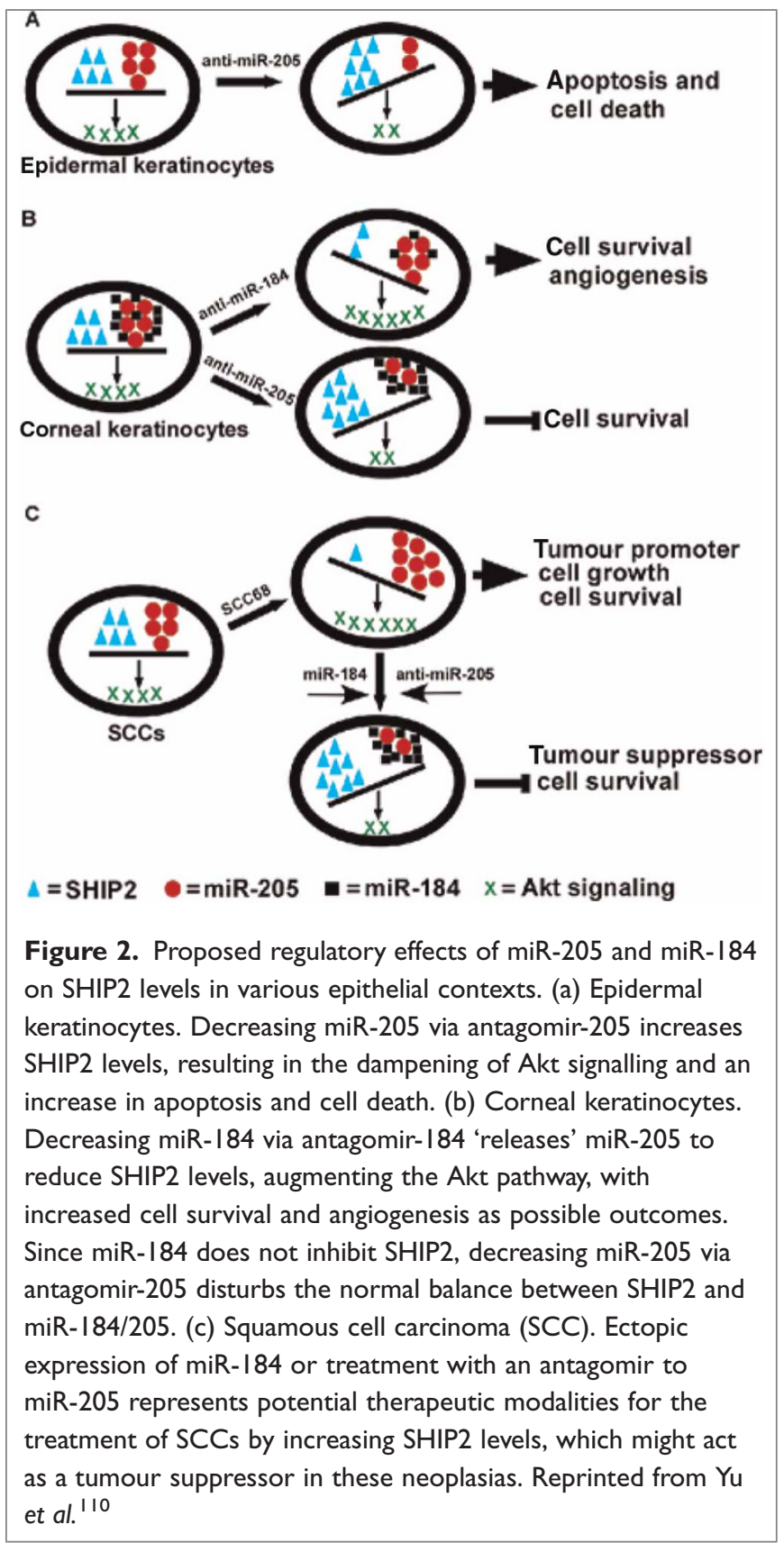

makes excellent biological sense from the perspective of corneal epithelial SCCs. These tumours develop from the stem cell-rich limbus rather than corneal epithelium. ${ }^{111}$ Since miR-184 is predicted to preserve SHIP2 levels by blocking miR-205, its presence in the corneal epithelium maintains a potential tumour suppressor. This could, in part, account for the rarity of corneal epithelial SCCs. Conversely, the abrupt absence of miR-184 in the limbal epithelium enables miR-205 negatively to regulate SHIP2 levels, decreasing the potential tumour suppressor function of SHIP2 in a stem cell-enriched region. As many neoplasias result from under-expressed tumour suppressor genes, downregulation of SHIP2 in limbal basal cells could contribute to the neoplastic transformation of these cells. As mentioned previously, miR-205 has an anti-apoptotic effect in keratinocytes. Because miR-205 is uniquely regulated by miR-184 in the corneal epithelium (Figure 2b), it is likely that such regulation affects Akt signalling and cell survival in corneal epithelial cells. The phosphatidylinositol 3-kinase/Akt signalling pathway has been shown to be upregulated during corneal epithelial wounding ${ }^{112}$ and to be responsible for protecting corneal epithelial cells from apoptosis. ${ }^{113}$ It has also been postulated that growth factors such as hepatocyte growth factor confer cytoprotection to corneal epithelial cells. ${ }^{113}$ It is likely that miR-205 functions in a similar cytoprotective manner. For example, wounding the corneal epithelium transiently downregulates miR-184, whereas miR-205 does not change. ${ }^{60}$ Loss of miR-184 in the corneal epithelium could enable miR-205 to have an anti-apoptotic action by positively regulating Akt signalling, thereby protecting the corneal epithelial cells during re-epithelialisation.

\section{Retinal MiRNAs of the mammalian eye}

As mentioned previously, an early report implicated miRNAs in the development of photoreceptors of the Drosophila eye. In this report, $\mathrm{Li}$ and Carthew ${ }^{58}$ showed that miR-7 is activated in cells undergoing differentiation into photoreceptors. These authors demonstrated that the transcription factor, Yan, repressed $\mathrm{miR}-7$ in the photoreceptor progenitor cells, and that EGFR signalling induced differentiation, triggering the degradation of Yan and, as a consequence, the upregulation of miR-7. Furthermore, it was shown that miR-7 targets the Yan message for translational repression, setting up a negative feedback loop that reinforces the 
mutually exclusive nature of these two factors. As with many developmental systems first described in Drosophila, numerous reports describing aspects of miRNA biology in the mammalian retina have since been published.

The authors' laboratory was among the first to describe the expression and spatial distribution of miRNAs in the murine retina. ${ }^{60} \mathrm{~A}$ number of highly abundant miRNAs were found; namely, miR-181a, -125b, -26a, -124a and let-7, in the retinal tissue of the murine eye. Karali et al. ${ }^{103}$ confirmed these observations, reporting on the presence of miR-124a, $-181 \mathrm{a},-9$ and $-29 \mathrm{c}$ in developing tissue of the mouse eye. With the exception of miR-124a, most of these miRNA molecules, particularly let-7 and miR-125bthe mammalian homologue of lin-4-are ubiquitously expressed throughout development in a wide range of tissues. ${ }^{19,32,60}$ In situ hybridisation of adult mouse retinal tissue showed a concentration of miR-181a in the innermost cells of the inner nuclear layer, with a second expression domain clearly evident in the ganglion cell layer. $^{60,103,114}$

Karali et al. ${ }^{103}$ were able to show that miR-124a is strongly present in all cell layers of the neural retina, the most intense staining being observed in the photoreceptor and bipolar cells. Many investigations have reported finding miR-124a in the retinas of a variety of mammalian and nonmammalian species. ${ }^{60,103,115,116}$ This miRNA is 100 per cent conserved in nucleotide sequences from flies to humans, and is expressed throughout the embryonic and adult central nervous systems of all species examined. ${ }^{19-21,31,33,63}$ Like the stratified squamous epithelial-specific miR-205, ${ }^{60,93,110}$ the neuronal miR-124a represents a class of miRNAs signifying tissue identity. ${ }^{117}$ One group reported finding miR-124 together with the neural-specific miR-7 in the lens tissues of mice and rats. ${ }^{117}$ Little evidence was found from either microarray or northern blot analyses of lens tissue to substantiate these findings. ${ }^{60}$ It therefore seems possible that the lens preparations used in this study may have been contaminated with small amounts of retinal and/or ciliary body tissue.
The expression of miR-124a is repressed by the RE1 silencing transcription factor (REST) in nonneuronal cells and neural progenitors. ${ }^{118}$ As neuronal cells differentiate from their progenitors, REST activity is downregulated, thereby removing transcriptional repression of the miR-124a gene. Increasing levels of miR-124a target the small C-terminal domain phosphatase 1 (SCP1), a co-repressor subunit of the REST complex, setting up a feedback loop that reinforces the differentiation process. ${ }^{119}$

Several groups, including that of the present authors, identified a second set of miRNAs, miR-182, -183 and -96, which were found to be expressed in a more retinal-specific manner. $^{60,103,114,120}$ These miRNAs were generally not found in other tissues of the mouse and were variably detected in the central nervous system, depending on the location from which this tissue was obtained. ${ }^{60,120}$ Signal intensities, both from microarrays and northern blots, showed that miR-182 was more abundant than miR-183, and that miR-96 levels were the lowest of the three. In situ hybridisation demonstrated that miR-182, miR-183 and miR-96 were expressed in overlapping domains of the neural retina. ${ }^{60,103,114,120}$ miR-182 was clearly seen in the rod photoreceptors of the outer nuclear layer and, to a lesser extent, in the bipolar cells of the inner nuclear layer. ${ }^{60}$ The staining pattern within these two locations was concentrated more at the synaptic regions of the specific cell types, rather than their cell bodies. ${ }^{60,103,114}$ miR-183 was found at significantly lower levels than miR-182 in the rod photoreceptors, showing a similar distribution of stain. It was only rarely detected in the inner nuclear layer, perhaps due to its lower expression level. ${ }^{60}$ miR-96 was expressed at such low levels that most in situ protocols failed to detect it. Using a more sensitive in situ protocol, $\mathrm{Xu}$ et al. ${ }^{120}$ were able to demonstrate co-localisation of all three miRNAs in both the photoreceptor and bipolar cell layers. In contrast to miR-181a and miR-124a, no signal was detected for these miRNAs in the ganglion cell layer, further highlighting their more exclusive retinal profile. ${ }^{60,103}$ The levels of these miRNAs increased dramatically (at least tenfold) during the postnatal period of 
retinal development, indicating that these miRNAs are upregulated as retinal progenitors differentiate into the various mature cell types. ${ }^{103,120}$

The genes for miR-183, miR-96 and miR-182 have been mapped to a common $4 \mathrm{~kb}$ region of mouse chromosome6qA3 and human chromosome7q32.2. ${ }^{32}$ They are arranged within this locus in the order, $183>96>182$, and their orientations with respect to transcription are the same. Zebrafish orthologues were arranged in an identical manner within a more compact $1 \mathrm{~kb}$ region. ${ }^{120} \mathrm{Xu}$ and colleagues ${ }^{120}$ found that the three miRNAs can be produced from a single polycistronic pri-miRNA transcript. This would explain the similarities of their expression profiles. Marked differences in the relative levels of each of the individual miRNAs could be attributed to differential processing of the primary transcript or to varying decay rates. It is conceivable that miR-182, which lies $\sim 4 \mathrm{~kb}$ downstream from the other two miRNAs, could also be produced as an alternative transcript, thereby allowing for its higher rate of production. Regardless, it has now been shown that all three miRNAs are produced in tissues of the inner ear, ${ }^{121}$ in the lingual and olfactory epithelium ${ }^{120}$ and in the cranial and dorsal root ganglia. ${ }^{103,122}$ Inspection of the region upstream of the miRNA cluster in both the mouse and human genomes identified regulatory binding sites for CHX10, OLF1, OTX1 and Pax2, transcription factors involved in various aspects of sensory organ development. ${ }^{120}$ It has been proposed that the miR-183/96/182 gene cluster plays a fundamental role, common to all sensory tissue. During the course of the authors' studies, trace amounts of miR-182 and miR-183 were consistently detected in the cornea, ${ }^{60}$ observations that can now be explained by the relatively high density of sensory nerve endings terminating within the basal layers of the corneal epithelium.

Members of the miR-183/96/182 gene cluster have considerable sequence similarity. At the $5^{\prime}$ end, seven of the eight nucleotides that comprise the seed sequence responsible for target site selection are identical. Such a degree of similarity would predict that these miRNAs would show extensive overlap in their downstream targets. Comparison of the target predictions for the individual miRNA identified 38 potential targets that were shared by all three miRNAs. The set of common targets included genes known to have important roles in sensory organ physiology and development. ${ }^{120}$

One particular miRNA, miR-204, was found in all of the major tissues of the eye, suggesting that it may represent an ocular-specific miRNA. ${ }^{60,103}$ miR-204 was equally abundant in RNA preparations from the cornea, lens and retina. Northern blot analysis consistently highlighted the presence of a doublet, suggesting that different molecular species of this miRNA are produced. ${ }^{60}$ Our in situ analysis demonstrated a high level of expression of miR-204 in the ciliary body of the retina, a finding that was confirmed by Karali et al. ${ }^{103}$ and Deo et al. ${ }^{123}$ These two groups reported that miR-204 was present in several locations of the adult murine retina, mainly concentrated in the retinal pigmented epithelium, the inner nuclear layer and the ganglion cell layer. Both of these groups also found high levels of miR-204 in the choroids plexus of the brain. Given that miR-204 is expressed in prospective retinal pigmented epithelium at very early (E10.5) embryonic stages of development, combined with the strong expression in both the pigmented and nonpigmented cells of the adult retina and ciliary body, Karali et al. ${ }^{103}$ suggest that this miRNA might be involved in the differentiation of pigmented and neuronal cells from their common precursor.

\section{Physiological consequences of retinal miRNAs}

miRNAs were found to influence the neurodegenerative process in the Drosophila eye. ${ }^{124}$ This study showed that loss of miRNA processing due to a dicer-1 mutation enhanced the degenerative process occurring in retinal cells of the eye. The key finding of this report was the discovery that bantam, a Drosophila miRNA, possesses protective properties that can counteract retinal degeneration. The neuroprotective properties of bantam could be the result of a previously described ability of this miRNA to regulate the pro-apoptotic gene hid. ${ }^{57}$ 
Retinitis pigmentosa, the most common form of retinal degeneration, is characterised by progressive photoreceptor cell death and eventually leads to blindness. ${ }^{125}$ Mutations within the rhodopsin gene account for $\sim 25$ per cent of autosomal dominant forms of the disease. ${ }^{126}$ Transgenic mice carrying a copy of the dominant rhodopsin mutation, Pro347Ser, have been used as an animal model of retinitis pigmentosa. ${ }^{127}$ Loscher et al. compared the expression profile of miRNAs in the degenerating retinas of these mice with those from normal wild-type mice. ${ }^{114}$ Expression levels of miR-96 and miR-183 decreased by more than threefold in the Pro347Ser retinas. This observation was not unexpected, given that one of the primary cell types, the photoreceptors, in which these two miRNAs are produced, is undergoing degeneration. $\mathrm{Xu}$ and colleagues ${ }^{120}$ found similar reductions in the levels of miR-182, -183 and -96 in the retinas of $r d 1 / r d 1$ mice.

Expression levels of miR-1 and miR-133 were markedly increased in the retinas of the Pro347Ser mice. Although miR-1 and -133 are clustered on the same chromosomal loci and are co-transcribed as a polycistronic pri-miRNA, they have distinct roles in the proliferation and differentiation of the tissues in which they are found. ${ }^{128}$ Most of the work carried out on these two miRNAs has focused on their roles in the development and maintenance of cardiac and skeletal muscle, their primary sites of activity. ${ }^{128-130}$ One of these studies reported significantly increased levels of miR-1 in cardiac ventricular cells in response to oxidative stress. ${ }^{130}$ Furthermore, the authors of this study found evidence that miR-1 downregulated HSP60 and HSP70, while miR-133 repressed caspase-9 expression. Such findings might contribute to a better understanding of the observations made by Loscher et al. ${ }^{114}$ on the degenerating retinas of Pro347Ser mice. In the course of writing this review, two groundbreaking reports appeared in the literature, describing a fundamental role for miR-133 in the process of tissue regeneration. ${ }^{131}$

$\mathrm{Xu}$ and colleagues ${ }^{120}$ found evidence of the circadian variation in expression of a number of retinal miRNAs. In particular, miR-182 and miR-96 were upregulated during the night phase of the 24-hour cycle. The presence of multiple binding sites for the transcription factor RORA, a central regulator of circadian rhythms, upstream of the miR-183/96/182 gene cluster was consistent with diurnal variations in the levels of these miRNAs. Similar studies carried out in Drosophila identified two highly homologous miRNAs, miR-263a and miR263b, which were upregulated in the night phase of the cycle. The sequences of these miRNAs were highly similar to the mammalian miR-183 and miR-182, suggesting that they may be Drosophila homologues. This being the case, the similarity in their diurnal variations is confirmatory. The mammalian miRNAs, miR182 and -96 , were both found to regulate the adenylate cyclase VI message through its $3^{\prime}$-UTR. Adenylate cyclase VI undergoes an opposing diurnal variation in response to the increased expression levels of miR-182 and -96 in the normal retina. In addition, these authors found the microphthalmia-associated transcription factor, MitF, was also targeted by miR-182 and -96.

In a study of ischaemia-induced retinal neovascularisation, miR-184 and miR-31 were substantially downregulated. ${ }^{132}$ It should be mentioned that several investigators ${ }^{120,127}$ found detectable traces of both these miRNAs in unperturbed retinal tissue of the mouse eye; however, the highest levels of miR-184 and -31 were concentrated in the lens and the cornea, two avascular tissues. ${ }^{60,103,110}$ Intraocular injection of miR-31 and -184 significantly reduced ischaemia-induced retinal neovascularisation. ${ }^{132}$ This would strongly suggest a role for these two miRNAs in the maintenance of an avascular state in the lens and cornea.

\section{Eyeing the ocular miRNA future}

Our understanding of the regulatory nature of miRNAs is likely to be in its infancy, and during the coming years, as more miRNA targets are discovered, greater insight into miRNA function will probably evolve. While, globally, interfering with miRNA synthesis and miRNA expression profiling of tissues has its place, a major effort should be directed at understanding the miRNA/target 
interactions. Emphasis should be placed on identifying the targets of 'eye-specific' miRNAs, such as has begun with miR-184 and needs to be done with miR-204, to name but two. There are inherent difficulties in identifying targets, as most miRNAs have several hundred putative targets; however, understanding the cellular localisation (eg apical versus basal, peripheral versus central) of a specific miRNA may provide insight into its potential target. For example, it is clear from in situ hybridisation analyses that miRNAs are rarely expressed throughout a photoreceptor cell, but rather have been observed in one specific part of the cell (eg miR-183's restriction to the outer nuclear layer $\left.{ }^{60}\right)$. Determining where a negative regulator exists may provide insight on the type of molecule it may regulate (receptor versus structural element). Another approach to understanding miRNA function is the generation of mice that are null for a specific miRNA. Aside from considerations of time and expense, one should think about the likelihood of observing a phenotype when eliminating a negative regulator. Given our understanding that many miRNAs are only required when cells and tissues are under non-homeostatic conditions (eg stress, cancer ${ }^{44}$ ), having an overt phenotype following a miRNA knock-out may be risky. For example, mice with a targeted deletion of miR-1-2, an important miRNA in regulating cardiac muscle function, ${ }^{43}$ showed no obvious differences in the external anatomy of the embryonic hearts, and skeletal muscle was grossly normal. ${ }^{133}$ Only $\sim 15$ per cent of the homozygous mice that survived had heart and ventricular dysfunction, whereas the remaining mice ( $~ 85$ per cent) were remarkably normal. ${ }^{133}$ It makes more sense to analyse a negative regulatory factor (eg miRNAs) through methods of overexpression. For example, overexpression of $\mathrm{miR}-1$ in the developing heart under the control of the $\beta$-myosin heavy chain promoter resulted in proliferation defects in ventricular cardiomyocytes and developmental arrest seen as early as E13.5. ${ }^{43}$ Another example of miRNA overexpression yielding a phenotype was recently described for miR-203. ${ }^{48}$ This miRNA is normally expressed in the suprabasal layers of the epidermis, and one of its targets is p63. ${ }^{48}$ Transgenic mice expressing miR-203 under the keratin 14 promoter resulted in ectopic expression of miR-203 in the basal layer of the epidermis, which repressed p63 and yielded a phenotype of a thinner epidermis when compared with wild-type mice. ${ }^{48}$ Another approach that has great utility in unravelling the role of a specific miRNA revolves around the use of antagomirs, which are cholesterol-linked single-stranded RNAs that are complementary to a specific miRNA and cause the depletion of the miRNA. ${ }^{134}$

Finally, antagomirs have been found to be very effective in knocking-down miRNAs when added directly to cultured human corneal epithelial cells. ${ }^{110}$ Besides being able to detect biochemical changes following miRNA knock-down, cells often undergo phenotypic changes, and in some cases (eg loss of miR-205) undergo apoptosis; all of which can provide information about miRNA function. ${ }^{110} \mathrm{~A}$ challenge will be to effectively deliver antagomirs to ocular tissues in vivo. At present, there is one report of in vivo delivery of an antagomir via tail vein injections into mice; ${ }^{134}$ however, the cost of such experiments is generally prohibitive. Partial success in eliminating a miRNA in the epidermis of neonatal mice via subcutaneous injections of an antagomir has been reported; however, this approach was not successful in adult mice. ${ }^{48}$

In conclusion, it is clear that many of the ocular miRNAs are tissue specific, and some progress has been made in understanding the functional significance of this specificity, although much more is needed. For example, in the corneal epithelium, miRNAs have been shown uniquely to regulate the expression of the lipid phosphatase, SHIP2 ${ }^{110}$ How this relates to corneal epithelial homeostasis is yet to be determined. In the lens, levels of miRNAs have been shown to vary during regeneration. It remains to be seen whether function can be ascribed to some of these up- and downregulated lens-associated miRNAs. In the retina, miRNAs have been shown to be involved in regulating the circadian rhythm and potentially regulating the retinal pigmentary epithelium. The levels of specific retinal miRNAs in a model of retinitis pigmentosa have been shown to 
change. Again, the functional significance of these observations needs to be determined. While much work needs to be done with respect to our understanding of how miRNAs regulate the various ocular tissues, it is likely that the next few years will see a remarkable increase in research directed towards this important effort.

\section{Acknowledgments}

We wish to acknowledge the provision of the floxed Dicer1 mouse, which was provided by Dr Tarakhovsky (Rockefeller University) and the LeCre mouse, which was provided by Dr Gruss (Max-Planck-Institute, Goettingen, Germany). Supported by National Institutes of Health Grant EY017536 (to R.M.L.).

\section{References}

1. Zamore, P.D. and Haley, B. (2005), 'Ribo-gnome: The big world of small RNAs', Science Vol. 309, pp. 1519-1524.

2. Eddy, S.R. (2001), 'Non-coding RNA genes and the modern RNA world', Nat. Rev. Genet. Vol. 2, pp. 919-929.

3. Cullen, B.R. (2004), 'Derivation and function of small interfering RNAs and microRNAs', Virus Res. Vol. 102, pp. 3-9.

4. Nakahara, K. and Carthew, R.W. (2004), 'Expanding roles for miRNAs and siRNAs in cell regulation', Curr. Opin. Cell Biol. Vol. 16, pp. $127-133$

5. Sontheimer, E.J. and Carthew, R.W. (2005), 'Silence from within: Endogenous siRNAs and miRNAs', Cell Vol. 122, pp. 9-12.

6. Fire, A., Xu, S., Montgomery, M.K., Kostas, S.A. et al. (1998), 'Potent and specific genetic interference by double-stranded RNA in Caenorhabditis elegans', Nature Vol. 391, pp. 806-811.

7. Hamilton, A.J. and Baulcombe, D.C. (1999), 'A species of small antisense RNA in posttranscriptional gene silencing in plants', Science Vol. 286, pp. 950-952.

8. Zamore, P.D., Tuschl, T., Sharp, P.A. and Bartel, D.P. (2000), 'RNAi: Double-stranded RNA directs the ATP-dependent cleavage of mRNA at 21 to 23 nucleotide intervals', Cell Vol. 101, pp. 25-33.

9. Hannon, G.J. (2002), 'RNA interference', Nature Vol. 418, pp. 244-251.

10. McManus, M.T. and Sharp, P.A. (2002), 'Gene silencing in mammals by small interfering RNAs', Nat. Rev. Genet. Vol. 3, pp. 737-747.

11. Tuschl, T. (2001), 'RNA interference and small interfering RNAs', Chembiochem. Vol. 2, pp. 239-245.

12. Bernstein, E., Caudy, A.A., Hammond, S.M. and Hannon, G.J. (2001), 'Role for a bidentate ribonuclease in the initiation step of RNA interference', Nature Vol. 409, pp. 363-366.

13. Hammond, S.M., Boettcher, S., Caudy, A.A., Kobayashi, R. et al. (2001), 'Argonaute2, a link between genetic and biochemical analyses of RNAi', Science Vol. 293, pp. 1146-1150.

14. Hutvagner, G., McLachlan, J., Pasquinelli, A.E., Balint, E. et al. (2001), 'A cellular function for the RNA-interference enzyme Dicer in the maturation of the let-7 small temporal RNA', Science Vol. 293, pp. $834-838$.

15. Filipowicz, W. (2005), 'RNAi: The nuts and bolts of the RISC machine', Cell Vol. 122, pp. 17-20.

16. Hutvagner, G. and Zamore, P.D. (2002), 'A microRNA in a multipleturnover RNAi enzyme complex’, Science Vol. 297, pp. 2056-2060.
17. Martinez, J., Patkaniowska, A., Urlaub, H., Luhrmann, R. et al. (2002), 'Single-stranded antisense siRNAs guide target RNA cleavage in RNAi', Cell Vol. 110, pp. 563-574.

18. Chen, P.Y., Manninga, H., Slanchev, K., Chien, M. et al. (2005), 'The developmental miRNA profiles of zebrafish as determined by small RNA cloning', Genes Dev. Vol. 19, pp. 1288-1293.

19. Lagos-Quintana, M., Rauhut, R., Yalcin, A., Meyer, J. et al. (2002), 'Identification of tissue-specific microRNAs from mouse', Curr. Biol. Vol. 12, pp. $735-739$.

20. Lau, N.C., Lim, L.P., Weinstein, E.G. and Bartel, D.P. (2001), 'An abundant class of tiny RNAs with probable regulatory roles in Caenorhabditis elegans', Science, Vol. 294, pp. 858-862.

21. Lee, R.C. and Ambros, V. (2001), 'An extensive class of small RNAs in Caenorhabditis elegans', Science Vol. 294, pp. 862-864.

22. Reinhart, B.J., Weinstein, E.G., Rhoades, M.W., Bartel, B. et al. (2002), 'MicroRNAs in plants', Genes Dev. Vol. 16, pp. 1616-1626.

23. Lee, R.C., Feinbaum, R.L. and Ambros, V. (1993), 'The C. elegans heterochronic gene lin-4 encodes small RNAs with antisense complementarity to lin-14', Cell Vol. 75, pp. 843-854.

24. Reinhart, B.J., Slack, FJ., Basson, M., Pasquinelli, A.E. et al. (2000), 'The 21-nt let-7 RNA regulates developmental timing in C. elegans', Nature Vol. 403, pp. 901-906.

25. Griffiths-Jones, S. (2004), 'The microRNA Registry', Nucleic Acids Res. Vol. 32, pp. D109-111.

26. Ambros, V., Bartel, B., Bartel, D.P., Burge, C.B. et al. (2003), 'A uniform system for microRNA annotation', RNA Vol. 9, pp. $277-279$.

27. Griffiths-Jones, S., Saini, H.K., van Dongen, S. and Enright, A.J. (2008), 'miRBase: Tools for microRNA genomics', Nucleic Acids Res. Vol. 36, pp. D154-158.

28. Lagos-Quintana, M., Rauhut, R., Lendeckel, W. and Tuschl, T. (2001), 'Identification of novel genes coding for small expressed RNAs', Science Vol. 294, pp. 853-858.

29. Pasquinelli, A.E., Reinhart, B.J., Slack, FJ., Martindale, M.Q. et al. (2000), 'Conservation of the sequence and temporal expression of let-7 heterochronic regulatory RNA', Nature Vol. 408, pp. 86-89.

30. Landgraf, P., Rusu, M., Sheridan, R., Sewer, A. et al. (2007), 'A mammalian microRNA expression atlas based on small RNA library sequencing', Cell Vol. 129, pp. 1401-1414.

31. Dostie, J., Mourelatos, Z., Yang, M., Sharma, A. et al. (2003), 'Numerous microRNPs in neuronal cells containing novel microRNAs', RNA Vol. 9, pp. 180-186.

32. Lagos-Quintana, M., Rauhut, R., Meyer, J., Borkhard, A. et al. (2003), 'New microRNAs from mouse and human', RNAVol. 9, pp. 175-179.

33. Sempere, L.F., Freemantle, S., Pitha-Rowe, I., Moss, E. et al. (2004), 'Expression profiling of mammalian microRNAs uncovers a subset of brain-expressed microRNAs with possible roles in murine and human neuronal differentiation', Genome Biol. Vol. 5, p. R13.

34. Kim, V.N. (2005), 'MicroRNA biogenesis: Coordinated cropping and dicing', Nat. Rev. Mol. Cell Biol. Vol. 6, pp. 376-385.

35. Lee, Y., Kim, M., Han, J., Yeom, K.H. et al. (2004), 'MicroRNA genes are transcribed by RNA polymerase II', EMBO J. Vol. 23, pp. $4051-4060$.

36. Cai, X., Hagedorn, C.H. and Cullen, B.R. (2004), 'Human microRNAs are processed from capped, polyadenylated transcripts that can also function as mRNAs', RNA Vol. 10, pp. 1957-1966.

37. Han, J., Lee, Y., Yeom, K.H., Kim, Y.K. et al. (2004), 'The Drosha-DGCR8 complex in primary microRNA processing', Genes Dev. Vol. 18, pp. 3016-3027.

38. Lund, E., Guttinger, S., Calado, A., Dahlberg, J.E. et al. (2004), 'Nuclear export of microRNA precursors', Science Vol. 303, pp. 95-98.

39. Okamura, K., Ishizuka, A., Siomi, H. and Siomi, M.C. (2004), 'Distinct roles for Argonaute proteins in small RNA-directed RNA cleavage pathways', Genes Dev. Vol. 18, pp. 1655-1666.

40. Esau, C., Kang, S., Peralta, E., Hanson, E. et al. (2004), 'MicroRNA-143 regulates adipocyte differentiation', J. Biol. Chem. Vol. 279 , pp. $52361-52365$. 
41. Hornstein, E., Mansfield, J.H., Yekta, S., Hu, J.K. et al. (2005), 'The microRNA miR-196 acts upstream of Hoxb8 and Shh in limb development', Nature Vol. 438, pp. 671-674.

42. Xu, P., Vernooy, S.Y., Guo, M. and Hay, B.A. (2003), 'The Drosophila microRNA Mir-14 suppresses cell death and is required for normal fat metabolism.', Curr. Biol. Vol. 13, pp. 790-795.

43. Zhao, Y., Samal, E. and Srivastava, D. (2005), 'Serum response factor regulates a muscle-specific microRNA that targets Hand2 during cardiogenesis', Nature Vol. 436, pp. 214-220.

44. Leung, A.K. and Sharp, P.A. (2007), 'MicroRNAs: A safeguard against turmoil?', Cell Vol. 130, pp. 581-585.

45. Bernstein, E., Kim, S.Y., Carmell, M.A., Murchison, E.P. et al. (2003), 'Dicer is essential for mouse development', Nat. Genet. Vol. 35, pp. 215-217.

46. Kanellopoulou, C., Muljo, S.A., Kung, A.L., Ganesan, S. et al. (2005), 'Dicer-deficient mouse embryonic stem cells are defective in differentiation and centromeric silencing', Genes Dev. Vol. 19, pp. 485-501.

47. Murchison, E.P., Partridge, J.F., Tam, O.H., Cheloufi, S. et al. (2005), 'Characterization of Dicer-deficient murine embryonic stem cells', Proc. Natl. Acad. Sci. USA Vol. 102, pp. 12135-12140.

48. Yi, R., Poy, M.N., Stoffel, M. and Fuchs, E. (2008), 'A skin microRNA promotes differentiation by repressing "stemness", Nature Vol. 452, pp. 225-229.

49. Calin, G.A. and Croce, C.M. (2006), 'MicroRNA signatures in human cancers', Nat. Rev. Cancer Vol. 6, pp. 857-866.

50. Kumar, M.S., Lu, J., Mercer, K.L., Golub, T.R. et al. (2007), 'Impaired microRNA processing enhances cellular transformation and tumorigenesis', Nat. Genet. Vol. 39, pp. 673-677.

51. Lu, J., Getz, G., Miska, E.A., Alvarez-Saavedra, E. et al. (2005), 'MicroRNA expression profiles classify human cancers', Nature Vol. 435, pp. 834-838.

52. Tavazoie, S.F, Alarco, C., Oskarsson, T., Padua, D. et al. (2008), 'Endogenous human microRNAs that suppress breast cancer metastasis', Nature Vol. 451, pp. 147-152.

53. Yu, S.L., Chen, H.Y., Yang, P.C. and Chen, J.J. (2007), 'Unique microRNA signature and clinical outcome of cancers', DNA Cell Biol. Vol. 26, pp. 283-292.

54. Zhang, B., Pan, X., Cobb, G.P. and Anderson, T.A. (2007), 'MicroRNAs as oncogenes and tumor suppressors', Dev. Biol. Vol. 302, pp. $1-12$.

55. Chang, S., Johnston, R.J.J., Frokjaer-Jensen, C., Lockery, S. et al. (2004), 'MicroRNAs act sequentially and asymmetrically to control chemosensory laterality in the nematode', Nature Vol. 430, pp. 785-798.

56. Johnston, R.J. and Hobert, O. (2003), 'A microRNA controlling left/ right neuronal asymmetry Caenorhabditis elegans', Nature Vol. 426, pp. $845-849$.

57. Brennecke, J., Hipfner, D.R., Stark, A., Russell, R.B. et al. (2003), bantam encodes a developmentally regulated microRNA that controls cell proliferation and regulates the proapoptotic gene hid in Drosophila', Cell Vol. 113, pp. 25-36.

58. Li, X. and Carthew, R.W. (2005), 'A microRNA mediates EGF receptor signaling and promotes photoreceptor differentiation in the Drosophila eye', Cell Vol. 123, pp. 1267-1277.

59. Chen, C.Z., Lodish, H.F and Bartel, D.P. (2004), 'MicroRNAs modulate hematopoietic lineage differentiation', Science Vol. 303, pp. 83-86.

60. Ryan, D.G., Oliveira-Fernandes, M. and Lavker, R.M. (2006), 'MicroRNAs of the mammalian eye display distinct and overlapping tissue specificity', Mol. Vis. Vol. 12, pp. 1175-1184.

61. Yekta, S., Shih, I.H. and Bartel, D.P. (2004), 'Micro-RNA-directed cleavage of HOXB8 mRNA', Science Vol. 304, pp. 594-596.

62. Kim, H.K., Lee, Y.S., Sivaprasad, U., Malhotra, A. et al. (2006), 'Muscle-specific microRNA miR-206 promotes muscle differentiation', J. Cell Biol. Vol. 174, pp. 677-687.

63. Wienholds, E., Kloosterman, W.P., Miska, E., Alvarez-Saavedra, E. et al. (2005), 'MicroRNA expression in zebrafish embryonic development', Science Vol. 309, pp. 310-311.
64. Lee, Y., Ahn, C., Han, J., Choi, H. et al. (2003), 'The nuclear RNase III Drosha initiates microRNA processing', Nature Vol. 425, pp. 415-419.

65. Hatfield, S.D., Shcherbata, H.R., Fischer, K.A., Nakahara, K. et al. (2005), 'Stem cell division is regulated by the microRNA pathway', Nature Vol. 435, pp. 974-978.

66. Carmell, M.A., Xuan, Z., Zhang, M.Q. and Hannon, G.J. (2002), 'The Argonate family: Tentacles that reach into RNAi, developmental control, stem cell maintenance, and tumorigenesis', Genes Dev. Vol. 16, pp. $2733-2742$.

67. Hutvagner, G. and Simard, M.J. (2008), 'Argonaute proteins: Key players in RNA silencing', Nat. Rev. Mol. Cell Biol. Vol. 9, pp. 22-32.

68. Peters, L. and Meister, G. (2007), 'Argonaute proteins: Mediators of RNA silencing', Mol. Cell. Vol. 26, pp. 611-623.

69. Cox, D.N., Chao, A., Baker, J., Chang, L. et al. (1998), 'A novel class of evolutionary conserved genes defined by piwi are essential for stem cell self-renewal', Genes Dev. Vol. 12, pp. 3715-3727.

70. Sharma, A.K., Nelson, M.C., Brandt, J.E., Wessman, M. et al. (2001), 'Human CD34(+) stem cells express the hiwi gene, a human homologue of the Drosophila gene piwi.', Blood Vol. 97, pp. 426-434.

71. Qiao, D., Zeeman, A.M., Deng, W., Looijenga, L.H. et al. (2002), 'Molecular characterization of of hiwi, a human member of the piwi gene family whose overexpression is correlated to seminomas', Oncogene Vol. 21, pp. 3988-3999

72. Kataoka, Y., Takeichi, M. and Uemura, T. (2001), 'Developmental roles and molecular characterization of a Drosophila homologue of Arabidopsis Argonaute1, the founder of a novel gene superfamily', Genes Cells Vol. 6, pp. $313-325$.

73. Liu, J., Carmell, M.A., Rivas, FV., Marsden, C.G. et al. (2004), 'Argonaute 2 is the catalytic engine of mammalian RNAi', Science Vol. 305, pp. 1437-1441.

74. Houbaviy, H.B., Murray, M.F and Sharp, P.A. (2003), 'Embryonic stem cell-specific microRNAs', Dev. Cell Vol. 5, pp. 351-358.

75. Lakshmipathy, U., Love, B., Goff, L.A., Jornsten, R. et al. (2007), 'MicroRNA expression pattern of undifferentiated and differentiated human embryonic stem cells', Stem Cells Dev. Vol. 16, pp. 1003-1016.

76. Suh, M.-R., Lee, Y., Kim, J.Y., Kim, S.-K. et al. (2004), 'Human embryonic stem cells express a unique set of microRNAs., Dev. Biol. Vol. 270, pp. $488-498$.

77. Tay, Y.M., Tam, W.L., Ang, Y.S., Gaughwin, P.M. et al. (2008), 'MicroRNA-134 modulates the differentiation of mouse embryonic stem cells, where it causes post-transcriptional attenuation of Nanog and LRH1', Stem Cells Vol. 26, pp. 17-29.

78. Lu, Y., Thomson, J.M., Wong, H.Y., Hammond, S.M. et al. (2007), 'Transgenic over-expression of the microRNA miR-17-92 cluster promotes proliferation and inhibits differentiation of lung epithelial progenitor cells', Dev. Biol. Vol. 310, pp. 442-453.

79. Ibarra, I., Erlich, Y., Muthuswamy, S.K., Sachidanandam, R. et al. (2007), 'A role for microRNAs in maintenance of mouse mammary epithelial progenitor cells', Genes Dev. Vol. 21, pp. 3238-3243.

80. Di Iorio, E., Barbaro, V., Ruzza, A., Ponzin, D. et al. (2005), 'Isoforms of DeltaNp63 and the migration of ocular limbal cells in human corneal regeneration', Proc. Natl. Acad. Sci. USA Vol. 102, pp. 9523-9528.

81. Mills, A.A., Zheng, B., Wang, X.J., Vogel, H. et al. (1999), 'p63 is a pp53 homologue required for limb and epidermal morphogenesis', Nature Vol. 398, pp. 708-713.

82. Pellegrini, G., Dellambra, E., Golisano, O., Martinelli, E. et al. (2001), 'p63 identifies keratinocyte stem cells', Proc. Natl. Acad. Sci. USA Vol. 98, pp. 3156-3161.

83. Senoo, M., Pinto, F, Crum, C.P. and McKeon, F. (2007), 'p63 is essential for the proliferative potential of stem cells in stratified epithelia', Cell Vol. 129, pp. 523-536.

84. Yang, A., Schweitzer, R., Sun, D., Kaghad, M. et al. (1999), 'p63 is essential for regenerative proliferation in limb, craniofacial and epithelial development', Nature Vol. 398, pp. 714-718. 
85. Miller, S.J., Lavker, R.M. and Sun, T.-T. (2005), 'Interpreting epithelial cancer biology in the context of stem cells: Tumor properties and therapeutic implications', Biophys. Biochem. Acta Vol. 1756, pp. 25-52.

86. Reya, T., Morrison, S.J., Clarke, M.F. and Weissman, I.L. (2001), 'Stem cells, cancer, and cancer stem cells', Nature Vol. 414, pp. 105-111.

87. Tu, S.M., Lin, S.H. and Logothetis, C.J. (2002), 'Stem-cell origin of metastasis and heterogeneity in solid tumours', Lancet Oncol. Vol. 3 , pp. $508-513$.

88. He, L., Thomson, J.M., Hermann, M.T., Hernandon-Monge, E. et al (2005), 'A microRNA polycistron as a potential human oncogene', Nature Vol. 435, pp. 828-833.

89. O’Donnell, K.A., Wentzel, E.A., Zeller, K.I., Dang, C.V. et al. (2005), 'c-Myc-regulated microRNAs modulate E2F1 expression', Nature Vol. 435, pp. 839-843.

90. Ambros, V. (2004), 'The functions of animal microRNAs', Nature Vol. 431, pp. 350-355

91. Andl, T., Murchison, E.P., Liu, F., Zhang, Y. et al. (2006), 'The miRNA-processing enzyme Dicer is essential for the morphogenesis and maintenance of hair follicles', Curr. Biol. Vol. 16, pp. 1041-1049.

92. Cobb, B.S., Nesterova, T.B., Thompson, E., Hertweck, A. et al. (2005), ' $\mathrm{T}$ cell lineage choice and differentiation in the absence of the RNase III enzyme Dicer', J. Exp. Med. Vol. 201, pp. 1367-1373.

93. Yi, R., O'Carroll, D., Pasolli, H.A., Zhang, Z. et al. (2006), 'Morphogenesis in skin is governed by discrete sets of differentially expressed microRNAs’, Nat. Genet. Vol. 38, pp. 356-362.

94. Chen, J.F., Murchison, E.P., Tang, R., Callis, T.E. et al. (2008), 'Targeted deletion of Dicer in the heart leads to dilated cardiomyopathy and heart failure', Proc. Natl. Acad. Sci. USAVol. 105, pp. 2111-2116.

95. Harris, K.S., Zhang, Z., McManus, M.T., Harfe, B.D. et al. (2006), 'Dicer function is essential for lung epithelium morphogenesis', Proc. Natl. Acad. Sci. USA. Vol. 103, pp. 2208-2213.

96. Lynn, F.C., Skewes-Cox, P., Kosaka, Y., McManus, M.T. et al. (2007), 'MicroRNA expression is required for pancreatic islet cell genesis in the mouse', Diabetes Vol. 56, pp. 2938-2945.

97. O’Rourke, J.R., Georges, S.A., Seay, H.R., Tapscott, S.J. et al. (2007), 'Essential role for Dicer during skeletal muscle development', Dev. Biol. Vol. 311, pp. 359-368.

98. Ashery-Padan, R., Marquardt, T., Zhou, X. and Gruss, P. (2000), 'Pax6 activity in the lens primordium is required for lens formation and for correct placement of a single retina in the eye', Genes Dev. Vol. 14, pp. 2701-2711.

99. St-Onge, L., Sosa-Pineda, B., Chowdhury, K., Mansouri, A. et al. (1997), 'Pax6 is required for differentiation of glucagon-producing alpha-cells in mouse pancreas', Nature Vol. 387, pp. 406-409.

100. Chow, R.L. and Lang, R.A. (2001), 'Early eye development in vertebrates', Ann. Rev. Cell Dev. Biol. Vol. 17, pp. 255-296.

101. Wei, Z.G., Sun, T.T. and Lavker, R.M. (1996), 'Rabbit conjunctival and corneal epithelial cells belong to two separate lineages', Invest. Ophthalmol. Vis. Sci. Vol. 37, pp. 523-533

102. Damiani, D., Alexander, J.J., O’Rourke, J.R., McManus, M. et al. (2008), 'Dicer inactivation leads to progressive functional and structural degeneration of the mouse retina', J. Neurosci. Vol. 28, pp. 4878-4887.

103. Karali, M., Peluso, I., Marigo, V. and Banfi, S. (2007), 'Identification and characterization of microRNAs expressed in the mouse eye', Invest. Ophthalmol Vis. Sci. Vol. 48, pp. 509-515.

104. Beebe, D.C. and Coats, J.M. (2000), 'The lens organizes the anterior segment: Specification of neural crest cell differentiation in the avian eye', Dev. Biol. Vol. 220, pp. 424-431.

105. Zak, N.B. and Linsenmayer, T.F. (1985), 'Analysis of corneal development with monoclonal antibodies. I. Differentiation in isolated corneas', Dev. Biol. Vol. 108, pp. 443-454.

106. Makarev, E., Spence, J.R., Del Rio-Tsonis, K. and Tsonis, P.A. (2006), 'Identification of microRNAs and other small RNAs from the adult newt eye', Mol. Vis. Vol. 12, pp. 1386-1391.

107. Tsonis, P.A., Call, M.K., Grogg, M.W., Sartor, M.A. et al. (2007), 'MicroRNAs and regeneration: Let-7 members as potential regulators of dedifferentiation in lens and inner ear hair cell regeneration of the adult newt', Biochem. Biophys. Res. Commun. Vol. 362, pp. 940-945.

108. Lewis, B.P., Shih, I.H., Jones-Rhoades, M.W., Bartel, D.P. et al. (2003), 'Prediction of mammalian microRNA targets', Cell Vol. 115 pp. 787-798.

109. Krek, A., Grun, D., Poy, M.N., Wolf, R. et al. (2005), 'Combinatorial microRNA target predictions', Nat. Genet. Vol. 37, pp. 495-500.

110. Yu, J., Ryan, D., Getsios, S., Oliveira-Fernandes, M. et al. (2008), 'MicroRNA-184 antagonizes microRNA-205 to maintain the lipid phosphatase SHIP2 levels in epithelia', Proc. Natl. Acad. Sci. USA Vol. 105, pp. 19300-19305.

111. Waring, G.O., Roth, A.M. and Ekins, M.B. (1984), 'Clinical and pathologic description of 17 cases of corneal intraepithelial neoplasia', Am. J. Ophthalmol. Vol. 97, pp. 547-559.

112. Xu, K.P., Yin, J. and Yu, F.S. (2006), 'SRC-family tyrosine kinases in wound- and ligand-induced epidermal growth factor receptor activation in human corneal epithelial cells', Invest. Ophthalmol. Vis. Sci. Vol. 47, pp. 2832-2839.

113. Kakazu, A., Chandrasekher, G. and Bazan, H.E. (2004), 'HGF protects corneal epithelial cells from apoptosis by the PI-3K/Akt-1/Bad- but not the ERK1/2-mediated signaling pathway', Invest. Ophthalmol. Vis. Sci. Vol. 45, pp. 3485-3492.

114. Loscher, C.J., Hokamp, K., Kenna, P.F, Ivens, A.C. et al. (2007), 'Altered retinal microRNA expression profile in a mouse model of retinitis pigmentosa', Genome Biol. Vol. 8, p. R248.

115. Arora, A., McKay, G.J. and Simpson, D.A. (2007), 'Prediction and verification of miRNA expression in human and rat retinas', Invest. Ophthalmol. Vis. Sci. Vol. 48, pp. 3962-3967.

116. Darnell, D.K., Kaur, S., Stanislaw, S., Konieczka, J.H. et al. (2006), 'MicroRNA expression during chick embryo development', Dev. Dyn. Vol. 235, pp. 3156-3165.

117. Frederikse, P.H., Donnelly, R. and Partyka, L.M. (2006), 'miRNA and Dicer in the mammalian lens: Expression of brain-specific miRNAs in the lens', Histochem. Cell Biol. Vol. 126, pp. 1-8.

118. Conaco, C., Otto, S., Han, J.J. and Mandel, G. (2006), 'Reciprocal actions of REST and a microRNA promote neuronal identity', Proc. Natl. Acad. Sci. U. S. A. Vol. 103, pp. 2422-2427.

119. Visvanathan, J., Lee, S., Lee, B., Lee, J.W. et al. (2007), 'The microRNA miR-124 antagonizes the anti-neural REST/SCP1 pathway during embryonic CNS development', Genes Dev. Vol. 21, pp. $744-749$.

120. Xu, S., Witmer, P.D., Lumayag, S., Kovacs, B. et al. (2007), 'MicroRNA (miRNA) transcriptome of mouse retina and identification of a sensory organ-specific miRNA cluster', J. Biol. Chem. Vol. 282, pp. 25053-25066.

121. Weston, M.D., Pierce, M.L., Rocha-Sanchez, S., Beisel, K.W. et al. (2006), 'MicroRNA gene expression in the mouse inner ear', Brain Res. Vol. 1111, pp. 95-104.

122. Kloosterman, W.P., Wienholds, E., de Bruijn, E., Kauppinen, S. et al. (2006), 'In situ detection of miRNAs in animal embryos using LNA-modified oligonucleotide probes', Nat. Methods Vol. 3, pp. 27-29.

123. Deo, M., Yu, J.Y., Chung, K.H., Tippens, M. et al. (2006), 'Detection of mammalian microRNA expression by in situ hybridization with RNA oligonucleotides', Dev. Dyn. Vol. 235, pp. 2538-2548.

124. Bilen, J., Liu, N., Burnett, B.G., Pittman, R.N. et al. (2006), 'MicroRNA pathways modulate polyglutamine-induced neurodegeneration', Mol. Cell Vol. 24, pp. 157-163.

125. Hartong, D.T., Berson, E.L. and Dryja, T.P. (2006), 'Retinitis pigmentosa', Lancet Vol. 368, pp. 1795-1809.

126. Dryja, T.P., McGee, T.L., Hahn, L.B., Cowley, G.S. et al. (1990), 'Mutations within the rhodopsin gene in patients with autosomal dominant retinitis pigmentosa', N. Engl. J. Med. Vol. 323, pp. 1302-1307.

127. Li, T., Snyder, W.K., Olsson, J.E. and Dryja, T.P. (1996), 'Transgenic mice carrying the dominant rhodopsin mutation P347S: Evidence for defective vectorial transport of rhodopsin to the outer segments', Proc. Natl. Acad. Sci. USA Vol. 93, pp. 14176-14181. 
128. Chen, J.F., Mandel, E.M., Thomson, J.M., Wu, Q. et al. (2006), 'The role of microRNA-1 and microRNA-133 in skeletal muscle proliferation and differentiation', Nat. Genet. Vol. 38, pp. 228-233.

129. Luo, X., Lin, H., Pan, Z., Xiao, J. et al. (2008), 'Down-regulation of miR-1/miR-133 contributes to re-expression of pacemaker channel genes HCN2 and HCN4 in hypertrophic heart', J. Biol. Chem. Vol. 283, pp. 20045-20052.

130. Xu, C., Lu, Y., Pan, Z., Chu, W. et al. (2007), 'The muscle-specific microRNAs miR-1 and miR-133 produce opposing effects on apoptosis by targeting HSP60, HSP70 and caspase-9 in cardiomyocytes', J. Cell Sci. Vol. 120, pp. 3045-3052.
131. Yin, V.P., Thomson, J.M., Thummel, R., Hyde, D.R. et al. (2008), 'Fgf-dependent depletion of microRNA-133 promotes appendage regeneration in zebrafish.', Genes Dev. Vol. 22, pp. 728-733.

132. Shen, J., Yang, X., Xie, B., Chen, Y. et al. (2008), 'MicroRNAs regulate ocular neovascularization', Mol. Ther. Vol. 16, pp. 1208-1216.

133. Zhao, Y., Ransom, J.F., Li, A., Vedantham, V. et al. (2007), 'Dysregulation of cardiogenesis, cardiac conduction, and cell cycle in mice lacking miRNA-1-2', Cell Vol. 129, pp. 303-317.

134. Krutzfeldt, J., Rajewsky, N., Braich, R., Rajeev, K.G. et al. (2005), 'Silencing of microRNAs in vivo with 'antagomirs', Nature Vol. 438, pp. $685-689$ 